\title{
Amebas de vida libre género Acanthamoeba
}

\author{
Free living Amoeba of Acanthamoeba genus
}

El primer reporte que indica que el género Acanthaoeba podría causar enfermedad en el hombre data de 1958 y correspondió a una prueba de calidad de la vacuna contra la poliomielitis en cultivos celulares, en la que aparecieron placas que se pensó, inicialmente, podrían haber sido inducidas por el virus polio, porque ratones y monos, posterior a la inoculación con fluidos provenientes de los cultivos, murieron a causa de una meningoencefalitis. Sin embargo, se encontró que las placas habían sido causadas por amebas cuyos trofozoítos y quistes fueron identificados como pertenecientes al género Acanthamoeba. La observación realizada por Culbertson y cols, de los animales muertos, permitió presumir su rol como patógeno para el hombre.

Acanthamoeba fue descrita primero por Castellanii, cuando reportó la presencia de una ameba en cultivos de Cryptococcus pararoseus. El género fue establecido, posteriormente, por Volkonsky en 1931. En la actualidad, es parte de la familia Acanthamoebidae y la identificación de género es relativamente fácil y se realiza utilizando criterios morfológicos. Para la diferenciación de especies se han aplicado criterios inmunológicos, bioquímicos, fisiológicos y moleculares, ya que los morfológicos resultan subjetivos y se ven alterados por las condiciones de cultivo. Algunos laboratorios han empleado para esta diferenciación análisis de fragmentos de restricción RFLP (Polimorfismo en el largo de fragmentos de restricción) para estudiar los clusters de cepas de Acanthamoeba. Incluso, se ha logrado la secuenciación completa del gen de la subunidad menor ribosomal del núcleo. Usando este criterio, Stothard y cols designaron 12 tipos de secuencias (genotipos) de T1 a T12. De este análisis se ha podido establecer, por ejemplo, que la mayoría de las cepas aisladas en cuadros de queratitis corresponderían al genotipo 4 .

El ciclo biológico de este parásito presenta dos estadios: trofozoíto y quiste, siendo el primero, la forma vegetativa, es decir, de alimentación activa y reproducción; y el segundo, la forma quística, de resistencia frente a condiciones ambientales adversas. En los diversos hábitats donde se han encontrado, desarrollan su ciclo biológico multiplicándose por división binaria de tipo metamitótico.

Los trofozoítos se presentan ameboideos, poco móviles y de unos 25 a $40 \mu \mathrm{m}$, poseen un citoplasma granuloso limitado por una estrecha zona ecto-citoplasmática hialina, de cuya superficie emergen numerosos y finos seudópodos de aspecto acicular, acantopodios que bordean también su ancho lobópodo polar. En su citoplasma se distingue un núcleo voluminoso 5 a $6 \mu \mathrm{m}$, provisto de un gran cariosoma y de finos gránulos cromáticos periféricos poco marcados, no siempre visibles. Además, de la presencia de numerosas vacuolas digestivas, se destaca la presencia de una vacuola contráctil muy activa.

Poder patógeno. En pacientes inmunocomprometidos se ha descrito compromiso neurológico como la meningoencefalitis granulomatosa amebiana (MGA) y cuadros cutáneos. En pacientes inmunocompetentes se observan cuadros de queratitis.
Los primeros reportes de queratitis por el género Acanthamoeba fueron publicados por Nagington y cols en 1974, en Gran Bretaña, y por Jones y cols, en 1975 en E.U.A. Varias especies se han descrito como agentes causales de estos cuadros, entre las que destacan $A$. castellanii, A polyphaga, $A$. hatchetti, $A$. culbertsoni. A. rhysodes, $A$. griffini, A. quina y A. lugdunensis. En los años '80, incluso, se hablaba de una epidemia de queratitis por Acanthamoeba, debido al aumento del número de casos por el uso masivo de los lentes de contacto, tanto con fines terapéuticos como también cosméticos. Es justamente este cuadro, el más común en Chile y el primer caso publicado data de 1993. Los síntomas más frecuentes incluyen: ojos rojos, lagrimeo constante y edema palpebral. Inicialmente, las amebas se restringen al epitelio corneal, luego invaden el estroma, causando un daño extensivo, con un cuadro que va desde una inflamación leve a grave. Una de las características más importantes es la presencia de un infiltrado estromal en forma de anillo.

Para el diagnóstico se han empleado el estudio del LCR y cortes de biopsia en cuadros de MGA. Para los cuadros cutáneos y de compromiso ocular se recurre a estudios

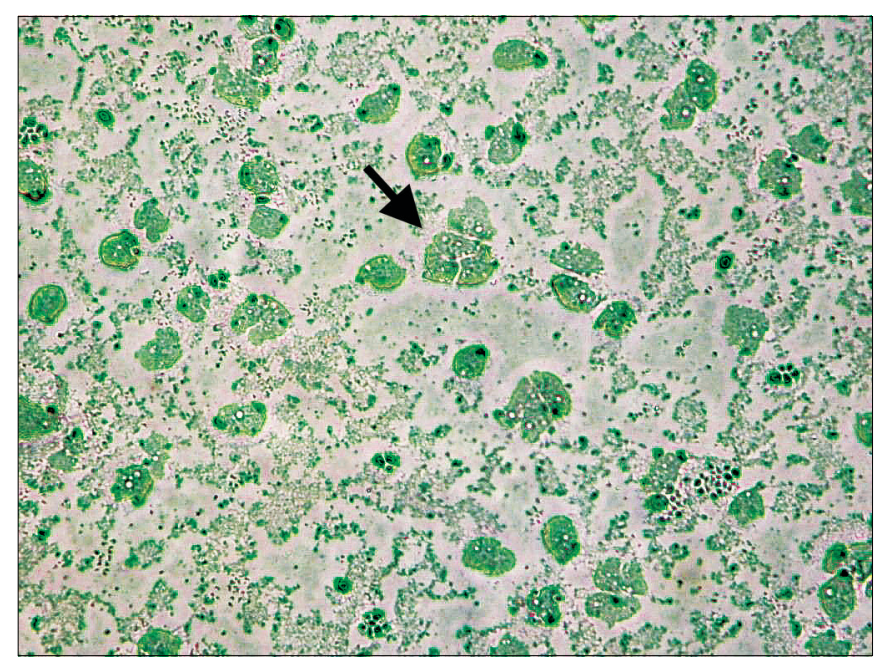

Figura 1. Trofozoítos de Acanthamoeba sp en cultivo aumento 10 X. Laboratorio de Referencia de Parasitología Cámara Nikon Coolpix 4500. 
de biopsia y cultivos. El medio de cultivo más utilizado es el no nutriente de Page y sobre éste se dispensa un tamiz bacteriano que, generalmente, corresponde a Escherichia coli. Éste se realiza, a diferentes temperaturas, por un lapso de 7 a 10 días y, si es positivo, se observarán trofozoítos y quistes con lo cuales se identificará el género al que corresponda.

\section{Referencias}

1.- Bottone E J. Free-Living Amebas of the genera Acanthamoeba and Naegleria: An overview and basic microbiologic correlates. Mount Sinai J Med 1993; 60: 260-70.

2.- Donoso R, Mura C J J, López M. Queratitis por acantoamoeba tratadas con propamidina y polihexametil biguanida (PHMB).

Rev Méd Chile 2002; 130; 396-401.

3.- Fenchel T. Ecology of Protozoa. The biology of free-living phagotrophic protists, Springer-Verlag. New York, U.S.A. 1987; p. 197.

4.- Fowler M, Carter R F. Acute pyogenic meningitis probably due to Acanthamoeba sp: A preliminary report. Br Med J 1965; 2: 740-3.

5.- Gottlieb B. Amebas de vida libre potencialmente patógenas "Parasitología Médica" Santiago Ed. Mediterráneo 1999; pp 302-5.

6.- Howe D K, Vodkin M H, Robert J N, Visvesvara G S, McLaughlin G L.

Identification of two genetic markers that distinguish pathogenic and nonpathogenic strains of Acanthamoeba spp. Parasitol Res 1997; 83: 345-34.

7.- Jonckheere J F. Ecology of Acanthamoeba. Rev Infect Dis 1991; 13 (Suppl 5): S385-7.

8.- Jonckheere J F. Isoenzyme and total protein analysis by agarose isoelectric focusing and taxonomy of the genus Acanthamoeba. J Protozool 1983; 30: 701-6.

9.- Ma P, Visvesvara G S, Martínez A J,
Theodore F H, Daggett P M, Sawyer T K. Naegleria and Acanthamoeba infections. Rev Infect Dis 1990; 12: 490-513.

10.- Marciano-Cabral F, Puffenbarger R, Cabral GA. The increasing importance of Acanthamoeba infections. J Euk Microbiol 2000; 47: 29-36.

11.- Page F C. A new key to freshwater and soil Gymnamoebae, freshwater biological association. Cumbria, England 1988; p. 122.

12.- Schuster F, Visvesvara G. Free-living amoebae as opportunistic and nonopportunistic pathogens of humans and animals. Int J Parasitol 2004; 34: 1001-27.

13.- Visvesvara G S, Martínez A J, Schuster F L, Leitch G J, Wallace S V, Sawyer T K, et al. Leptomyxid ameba, a new agent of amebic meningoencephalitis in humans and animals. J Clin Microbiol 1990; 28: 2750-6.

14.- Vodkin M H, Howe D K, Visvesvara G S, McLaughlin G L. Identification of Acanthamoeba at the generic and specific levels using the polymerase chain reaction. J Protozool 1992; 39: 378-85.

M. Isabel Jercic L.

Instituto de Salud Pública de Chile Sección Parasitología 